\title{
Anionic redox effect on the electrochemical performance of $\mathrm{LLNMC}-\mathrm{CeO}_{2}-\mathrm{C}$ nanocomposites
}

\author{
K. A. Kurilenko ${ }^{1}$, D. I. Petukhov ${ }^{1,2, *}$, A. V. Garshev ${ }^{1,2}$, O. A. Shlyakhtin ${ }^{1}$ \\ ${ }^{1}$ Department of Chemistry, M.V. Lomonosov Moscow State University, 119991 Moscow, Russia \\ ${ }^{2}$ Department of Materials Sciences, M. V. Lomonosov Moscow State University, 119991 Moscow, Russia \\ *di.petukhov@gmail.com
}

PACS 61.46+w. 61.72.Ww, 66.10.Ed

DOI 10.17586/2220-8054-2018-9-6-775-782

\begin{abstract}
$\mathrm{Li}\left[\mathrm{Li}_{0.13} \mathrm{Ni}_{0.2} \mathrm{Mn}_{0.47} \mathrm{Co}_{0.2}\right] \mathrm{O}_{2}-\mathrm{CeO}_{2}$ composites have been obtained by coprecipitation with $\mathrm{CeO}_{2}$ and by coating with ceria followed by coating with carbon film. STEM analysis revealed the formation of $20-30 \mathrm{~nm}$ ceria particles on the surface of LLNMC grains in all cases. Both carbon-coated LLNMC-CeO $\mathrm{O}_{2}$ composites and carbon-free LLNMC coated with $1 \% \mathrm{CeO}_{2}$ demonstrated enhanced capacity values that could not be explained by the charge compensation via redox of nickel and cobalt. $5 \% \mathrm{CeO}_{2}$-coprecipitated sample demonstrated the most intense anomaly in $\mathrm{CV}$ at $U=4.1-4.5 \mathrm{~V}$ associated with redox processes in the anionic sublattice of LLNMC and a larger charge transfer resistance compared to other composites. The maximum values of $\mathrm{Li}^{+}$diffusion coefficient have been observed for the samples coated with $1 \% \mathrm{CeO}_{2}$. The different electrochemical behavior of these samples could be explained by the different intensity of anionic redox processes in the samples with different amount of nanocrystalline ceria.
\end{abstract}

Keywords: Li-ion batteries, cathode materials, coatings, ceria, pyrolytic carbon.

Received: 19 November 2018

\section{Introduction}

$\mathrm{Li}(\mathrm{Li}, \mathrm{Ni}, \mathrm{Co}, \mathrm{Mn}) \mathrm{O}_{2}$ (Li-rich LNMC, LLNMC) is one of the most promising groups of cathode materials for Li-ion batteries. The main advantage of these materials deals with their high specific energy due to the rather high discharge voltage and the enhanced discharge capacity $[1,2]$. The reasons for the unusually high discharge capacity values have not been fully understood until now. It is proven experimentally that the valence states of $\mathrm{Ni}$, Co and $\mathrm{Mn}$ in the hexagonal lattice of LLNMC are 2+, 3+ and 4+, respectively [3]. In order to sustain the electroneutrality, the deintercalation of lithium during charging the battery is accompanied by the increase in valence states of $\mathrm{Ni}$ and Co to $4+$ while the valence state of $\mathrm{Mn}$ remains the same. The highest discharge capacity values that could be achieved in frames of this charge compensation mechanism are $170-180 \mathrm{mAh} \mathrm{g}^{-1}$ while the experimentally observed values often exceed $200 \mathrm{mAh} \mathrm{g}^{-1}$.

The enhanced capacity of LLNMC compounds with the composition that can be interpreted as $x \mathrm{Li}_{2} \mathrm{MnO}_{3}$. $y \mathrm{LiMeO}_{2}(\mathrm{Me}=\mathrm{Ni}, \mathrm{Co}, \mathrm{Mn})$ could be explained in terms of the activation model [4-6]. According to this theory, the deintercalation of lithium at $U>4.6 \mathrm{~V}$ during the first cycles is accompanied by the electrochemical decomposition of $\mathrm{Li}_{2} \mathrm{MnO}_{3}$ component and the formation of $\mathrm{MnO}_{2}$ that attends further cycling. An essential feature of this process, called the activation of cathode materials, is fast decrease of discharge capacity during first several cycles followed by the stabilization of capacity at $220-240 \mathrm{mAh} \mathrm{g}^{-1}$. Due to the irreversibility of electrochemical decomposition of $\mathrm{Li}_{2} \mathrm{MnO}_{3}$, the Coulombic efficiency of first cycles is unusually low. The information on the evolution of gaseous oxygen during the activation process is rather contradictory; several groups did not observe this process during cycling [7]. In order to explain this feature, the alternative model of the activation process was proposed based on the involvement of the anionic sublattice of LLNMC in the redox processes during cycling [8-10]. The formation of the unusual oxygen species in the LLNMC during cycling was recently confirmed experimentally by several spectroscopic methods [7-10].

Recent studies of the LLNMC-based cathode materials with various protecting coatings demonstrated that the better cycling stability of coated materials is often accompanied by the enhancement of these materials' capacity values [11-14]. This enhancement is observed not only at high but also at low discharge rates and after the first cycles. These enhanced capacity values also often exceeded $170-180 \mathrm{mAh} \mathrm{g}^{-1}$, which could not be attributed to the increase in valence states of $\mathrm{Co}$ and $\mathrm{Ni}$ only. Other signs indicating the activation process (fast capacity fade and anomalously low Coulombic efficiency at first cycles) were also not observed in the coated cathode materials. In the case of $\mathrm{CeO}_{2}$, the capacity enhancement effect was observed not only for the $\mathrm{CeO}_{2}$-coated LLNMC but also for the $\mathrm{CeO}_{2}$-doped cathode material when the dopant was introduced during the synthesis of LLNMC [15]. 
Systematic studies of the relationships between these materials' enhanced electrochemical performance and redox processes in their anionic sublattice have not been performed until now. Taking into account these considerations, the present study deals with the comparative analysis of electrochemical performance of LLNMC-based cathode material doped with $\mathrm{CeO}_{2}$ by various methods in order to explore the relationships of their enhanced properties with redox processes in the oxygen sublattice of LLNMC. As the amount of $\mathrm{CeO}_{2}$ that caused the maximum enhancement of electrochemical properties was different for $\mathrm{CeO}_{2}$-coated and $\mathrm{CeO}_{2}$-coprecipitated cathode materials, the samples were selected for the analysis that demonstrated the maximum $\mathrm{CeO}_{2}$ doping effect.

\section{Experimental}

A synthesis of $\mathrm{Li}\left[\mathrm{Li}_{0.13} \mathrm{Ni}_{0.2} \mathrm{Mn}_{0.47} \mathrm{Co}_{0.2}\right] \mathrm{O}_{2}$ composites with $\mathrm{CeO}_{2}$ was performed by using $\mathrm{Ni}\left(\mathrm{NO}_{3}\right)_{2} \cdot 6 \mathrm{H}_{2} \mathrm{O}$ (Reachim, analytical grade), $\mathrm{Mn}\left(\mathrm{NO}_{3}\right)_{2} \cdot 6 \mathrm{H}_{2} \mathrm{O}$ ("Alfa Aesar, $98 \%+$ ), $\mathrm{Co}\left(\mathrm{NO}_{3}\right)_{2} \cdot 6 \mathrm{H}_{2} \mathrm{O}$ (Reachim, analytical grade), $\mathrm{Ce}\left(\mathrm{NO}_{3}\right)_{3} \cdot 6 \mathrm{H}_{2} \mathrm{O}$ (Reachim, analytical grade), $\mathrm{LiOH} \cdot \mathrm{H}_{2} \mathrm{O}$ (Acros Organics, extra pure).

In order to obtain $\mathrm{Li}\left[\mathrm{Li}_{0.13} \mathrm{Ni}_{0.2} \mathrm{Mn}_{0.47} \mathrm{Co}_{0.2}\right] \mathrm{O}_{2}$, the mixed hydroxide $\left.\mathrm{Ni}_{0.23} \mathrm{Mn}_{0.54} \mathrm{Co}_{0.23}\right)(\mathrm{OH})_{n}$ was coprecipitated from $1 \mathrm{M}$ nitrate solution of corresponding salts by $0.2 \mathrm{M} \mathrm{LiOH}$ at $T=50^{\circ} \mathrm{C}$ and $\mathrm{pH}=11$ under intense stirring. After careful washing by water and acetone, the filtered residue was dried in air at $80{ }^{\circ} \mathrm{C}$ overnight. The obtained powder was mixed with corresponding amount of $\mathrm{LiOH} \cdot \mathrm{H}_{2} \mathrm{O}$ and heated under air at $500{ }^{\circ} \mathrm{C}(4 \mathrm{hrs})$ and $850{ }^{\circ} \mathrm{C}(12 \mathrm{hrs})$. To introduce $5 \mathrm{wt} . \% \mathrm{CeO}_{2}$ by coprecipitation, corresponding amount of $\mathrm{Ce}\left(\mathrm{NO}_{3}\right)_{3} \cdot 6 \mathrm{H}_{2} \mathrm{O}$ was added to the starting solution. To coat $\mathrm{Li}\left[\mathrm{Li}_{0.13} \mathrm{Ni}_{0.2} \mathrm{Mn}_{0.47} \mathrm{Co}_{0.2}\right] \mathrm{O}_{2}$ with $\mathrm{CeO}_{2}$ (1 wt.\%), LLNMC powder was soaked with cerium nitrate solution in ethyl alcohol, dried and calcined at $600{ }^{\circ} \mathrm{C} . \mathrm{CeO}_{2}$-coated LLNMC was soaked with a polystyrene solution in benzene (polystyrene/LLNMC $=1 / 6$ ), dried and calcined at $450{ }^{\circ} \mathrm{C}$ under argon.

XRD studies were performed by using D/MAX 2500 diffractometer (Rigaku) in the reflection mode with $\mathrm{CuK} \alpha$ radiation and $\mathrm{Ge}$ monochromator $\left(2 \Theta\right.$ range $10-90^{\circ}$, step $0.02^{\circ}$, acquisition time $\left.3 \mathrm{~s}\right)$. Analysis of diffraction patterns was performed by using WinXPow software and PDF-2 powder diffraction database.

The morphology and the composition of composite particles were analyzed by the transmission electron microscope Libra $200 \mathrm{MC}$ (Carl Zeiss) (accelerating voltage $200 \mathrm{kV}$; magnification $30-300 \mathrm{kX}$ ) equipped with an EDX analysis accessory X-Max 80T detector and Aztec TEM software (Oxford Inc., England). Carbon distribution micrographs have been calculated from the data obtained by means of energy filtered transmission electron microscopy (EFTEM) using three windows method.

The cathode mass containing $85 \mathrm{wt} . \%$ of $\mathrm{LLNMC}-\mathrm{CeO}_{2}-\mathrm{C}$ composite, $10 \%$ of acetylene black and polyvinylidene fluoride (5 wt.\%, soluted in N-methyl-2-pyrrolidone) was coated on a stainless steel net ( $0.05 \mathrm{~mm}$ thick), pressed and dried in vacuum $(\sim 1 \mathrm{mbar})$ at $T=120{ }^{\circ} \mathrm{C}$ for $8 \mathrm{hrs}$. The electrochemical measurements were performed in the Teflon 3-electrode cells containing an active electrode, Li counter-electrode and Li reference electrode separated with a porous polypropylene membrane soaked with electrolyte $\left(1 \mathrm{M} \mathrm{LiClO}_{4}\right.$ solution in the mixture of propylene carbonate-dimethoxyethane ( $7: 3$ by volume). According to the Fischer titration data by KF 684 (Metrohm, Switserland), the water content in the electrolyte did not exceed $25 \mathrm{ppm}$.

The galvanostatic curves and cyclic voltammograms (CV) were registered using Potentiostat-Galvanostat $100 \mathrm{~N}$ Metrohm Autolab (Metrohm, Switzerland) in the potential range $2 \div 4.6 \mathrm{~V}$ at room temperature. The current density during cycling was $20 \mathrm{mAg}^{-1}$; the potential scan rate during $\mathrm{CV}$ measurements was $50 \mu \mathrm{Vs}^{-1}$.

The data of the electrochemical impedance spectroscopy (EIS) were acquired using Solartron 1255B. The amplitude of the AC signal was $5 \mathrm{mV}$ over a frequency range from $1 \mathrm{MHz}$ to $10 \mathrm{mHz}$. The obtained hodographs were treated using ZView-Impedance software.

\section{Results and discussion}

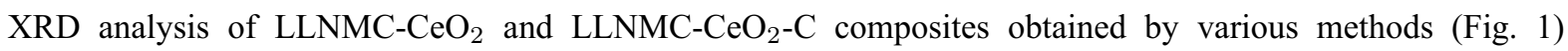
revealed the formation of perfectly ordered hexagonal lattice (space group $\mathrm{R} \overline{3} \mathrm{~m}$ ) in the lack of secondary phases in all cases in study. Significant splitting of 018/110 and 006/012 reflections indicates the low level of ion mixing in all these samples that was not affected by the $\mathrm{CeO}_{2}$ doping and the interaction with polystyrene pyrolysis byproducts during coating of LLNMC with carbon. The presence of $\mathrm{CeO}_{2}$ is clearly observed even in the sample with $1 \mathrm{mass} \% \mathrm{CeO}_{2}$.

STEM micrographs demonstrate the formation of 20-30 nm small spherical particles at the surface of $150-$ $200 \mathrm{~nm}$ sized grains (Fig. 2A-C). STEM-EDX analysis data of these samples show that larger grains consist of LLLNMC while smaller particles at their surface are $\mathrm{CeO}_{2}$. Several authors observed the formation of thin ceria film during coating [11-16] though in the most cases the coating with $\mathrm{CeO}_{2}$ by various methods resulted in the formation of individual spherical $\mathrm{CeO}_{2}$ particles [13-15,17,18]. Apart from $\mathrm{CeO}_{2}$ coating, thin films of pyrolytic 


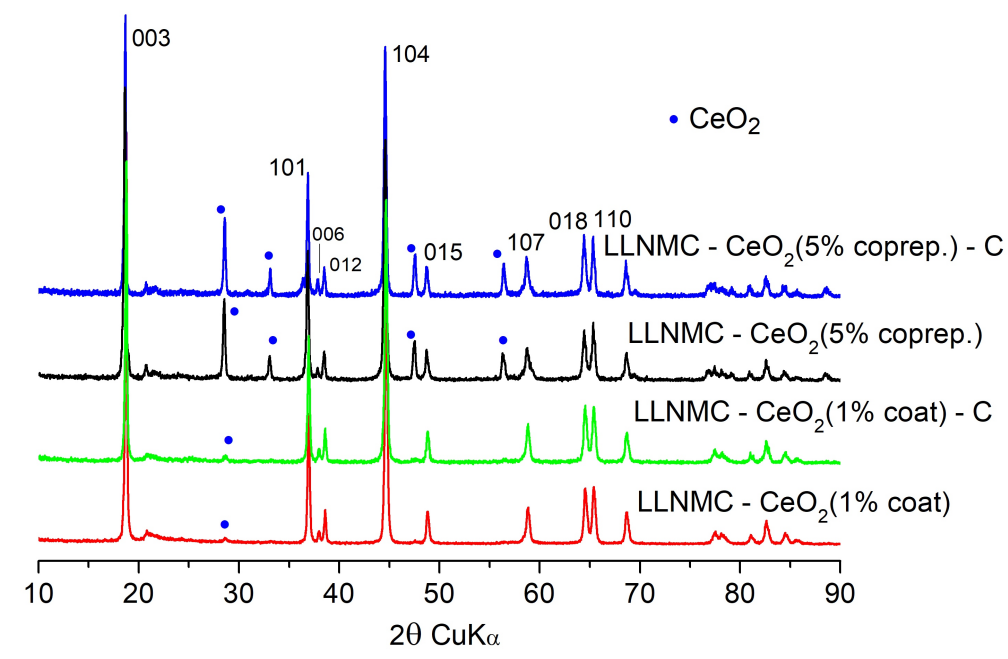

FIG. 1. XRD patterns of $\mathrm{Li}\left[\mathrm{Li}_{0.13} \mathrm{Ni}_{0.2} \mathrm{Mn}_{0.47} \mathrm{Co}_{0.2}\right] \mathrm{O}_{2}$ composites with $\mathrm{CeO}_{2}$ and carbon

carbon at the surface of LLNMC grains are continuous, as it could be observed in energy filtered TEM (EFTEM) micrographs (Fig. 2D,E).

Analysis of the electrochemical performance of these samples demonstrates that the behavior of the sample doped with $5 \% \mathrm{CeO}_{2}$ by coprecipitation is different from other ones. First of all, it concerns the absence of peaks at $U=4.2-4.5$ in the anodic branch of cyclic voltammetry curves while these peaks are clearly observed for other samples; however, positions of other peaks corresponding to $\mathrm{Ni}^{2+} \leftrightarrow \mathrm{Ni}^{4+}$ and $\mathrm{Co}^{3+} \leftrightarrow \mathrm{Co}^{4+}$ redox processes are almost the same for all these samples (Fig. 3). The introduction of lithium ions into LLNMC lattice during the galvanostatic discharge of $5 \%$ (coprep.) doped sample occurs also at $0.2-0.45 \mathrm{~V}$ lower potentials than in other samples (Fig. 4). A discharge capacity of this sample $\left(170 \mathrm{mAh} \mathrm{g}^{-1}\right)$ corresponds to the charge compensation mechanism by the change in valence states of nickel and cobalt in the lack of any other anomalies. The characteristic features of CV and galvanostatic curves of LLNMC-based composites are listed in the Table 1.

Instead, discharge capacities of other composites are considerably higher and could not be explained in the framework of this charge compensation model. This discrepancy implies the contribution of alternative redox processes to the charge compensation during lithium intercalation-deintercalation in the course of cycling. Apart from $5 \%$ (coprep.)-doped sample, the CV curves of other three composites display significant anomalies at $U=4.1-$ $4.5 \mathrm{~V}$ both in anodic and cathodic branches of their CV curves (Fig. 3). The most intensive effects are observed for the $5 \%$ (coprep.)-doped sample coated with carbon. According to recent studies, the redox effects in this potential range are associated with the reversible redox processes in the anionic sublattice of LLNMC [2, 19, 20]. In this case, deintercalation of lithium at $\mathrm{U}>4.1 \mathrm{~V}$ is accompanied by the formation of unusual oxygen species like peroxides $\mathrm{O}_{2}^{2-}[7,8,10]$ or the individual holes on the lattice oxygen [9]. The intercalation of lithium back to LLNMC during discharge is accompanied in these cases by the reduction of unusual oxygen species back to the common $\mathrm{O}^{2-}$. Hence, the enhanced capacity values of the both $1 \%$ (coat) and $5 \%$ (coprep.)-C composites could be associated with the switching on the anionic redox processes at $U>4.1$ during their cycling. The reasons for the oxygen passivation in the $5 \%$ (coprep.) composite sample without carbon coating are not clear now and need more detailed investigation.

The analysis of the electrochemical performance of the composite samples by the electrochemical impe- dance spectroscopy also revealed the difference in their electrochemical behavior (Fig. 5A-D). The equivalent circuit model used to fit the impedance spectra of these samples (Fig. 5E) involved the solution resistance of the cell $R_{e}$; the $\mathrm{Li}^{+}$migration resistance and the capacity of surface layers $R_{f}$ and $C_{f} . R_{c t}$ and $C_{c t}$ are the charge transfer resistance and the double layer capacitance, respectively. $Z_{w}$ corresponds to the diffusion-controlled Warburg impedance. It is considered that the electric contact between electrochemically-active LLNMC grains is performed by the randomly distributed conducting particles.

The impedance spectra of the samples at $U=3.5-3.8 \mathrm{~V}$ are rather similar and display high and stable charge transfer resistance and surface layer resistance for all samples in study. However, further increase of potential results in the appearance of two separate semicircles for the $5 \%$ (coprep.)-C composite sample that correspond to the charge transfer resistance and the resistance of the surface layer. At $U=4-4.1 \mathrm{~V}$, this process is accompanied 


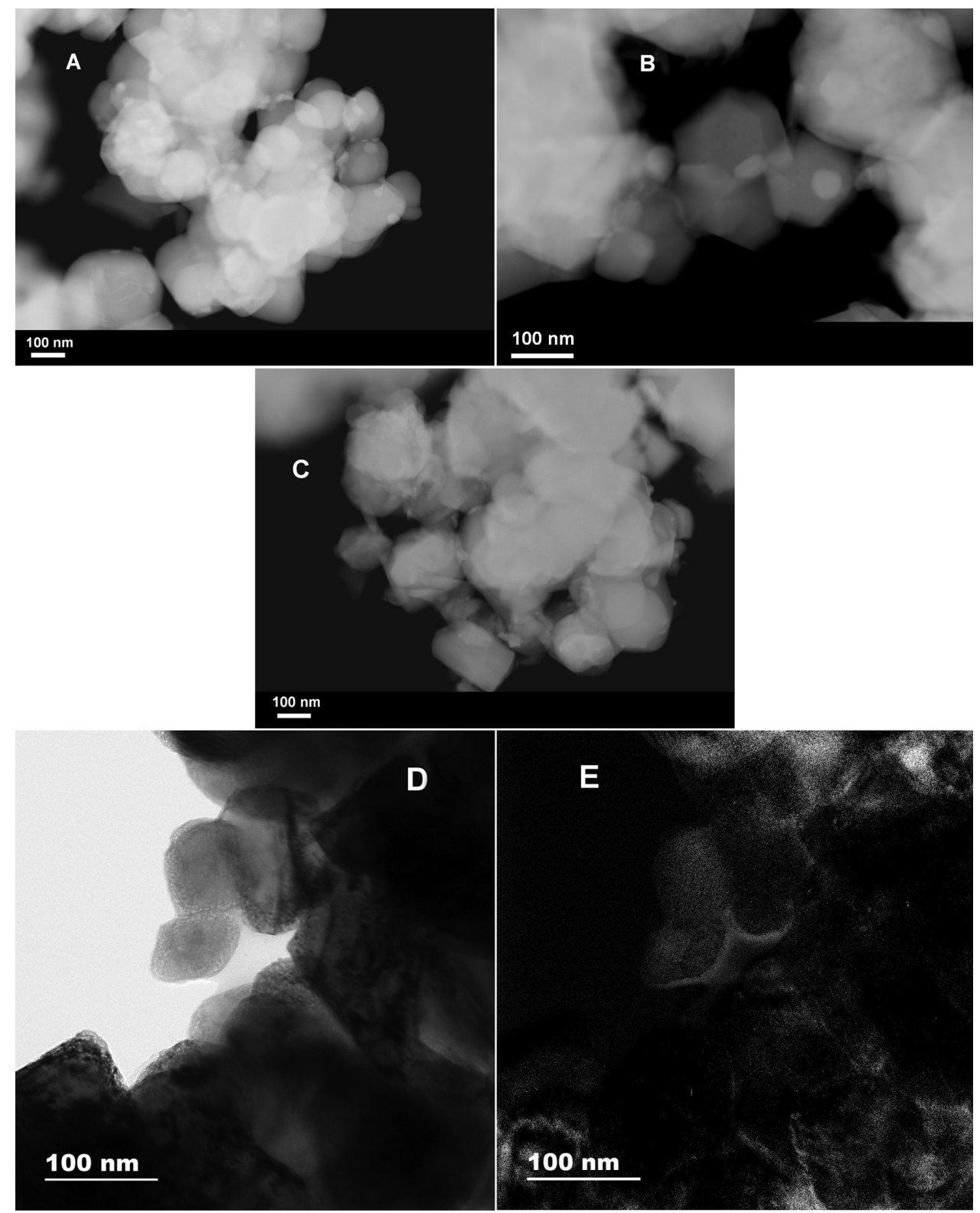

FIG. 2. (A-C) STEM micrographs of various composites: (A) - LLNMC - $\mathrm{CeO}_{2}(1 \%$, coating); (B) -LLNMC $-\mathrm{CeO}_{2}\left(5 \%\right.$, coprecipitation); (C) - LLNMC $-\mathrm{CeO}_{2}(1 \%$, coating) - C; (D, E) EFTEM micrographs of LLNMC $-\mathrm{CeO}_{2}(5 \%$, coprecipitation $)-\mathrm{C}$

TABLE 1. Characteristic features of CV and galvanostatic curves of LLNMC-based composites

\begin{tabular}{|c|c|c|c|c|}
\hline Sample & $\begin{array}{c}\text { Main anodic } \\
\text { peak, V }\end{array}$ & $\begin{array}{c}\text { Main cathodic } \\
\text { peak, V }\end{array}$ & $\begin{array}{c}\Delta \text { (anodic- } \\
\text { cathodic), V }\end{array}$ & $\begin{array}{c}\text { Mean discharge } \\
\text { potential, V }\end{array}$ \\
\hline LLNMC $-\mathrm{CeO}_{2}(1 \%$, coat $)$ & 3.98 & 3.66 & 0.32 & 3.68 \\
\hline LLNMC- $\mathrm{CeO}_{2}(1 \%$, coat $)-\mathrm{C}$ & 3.99 & 3.68 & 0.31 & 3.52 \\
\hline LLNMC- $\mathrm{CeO}_{2}(5 \%$, coprep$)-\mathrm{C}$ & 4.02 & 3.71 & 0.31 & 3.75 \\
\hline LLNMC $-\mathrm{CeO}_{2}(5 \%$, coprep$)$ & 3.93 & 3.68 & 0.25 & 3.3 \\
\hline
\end{tabular}




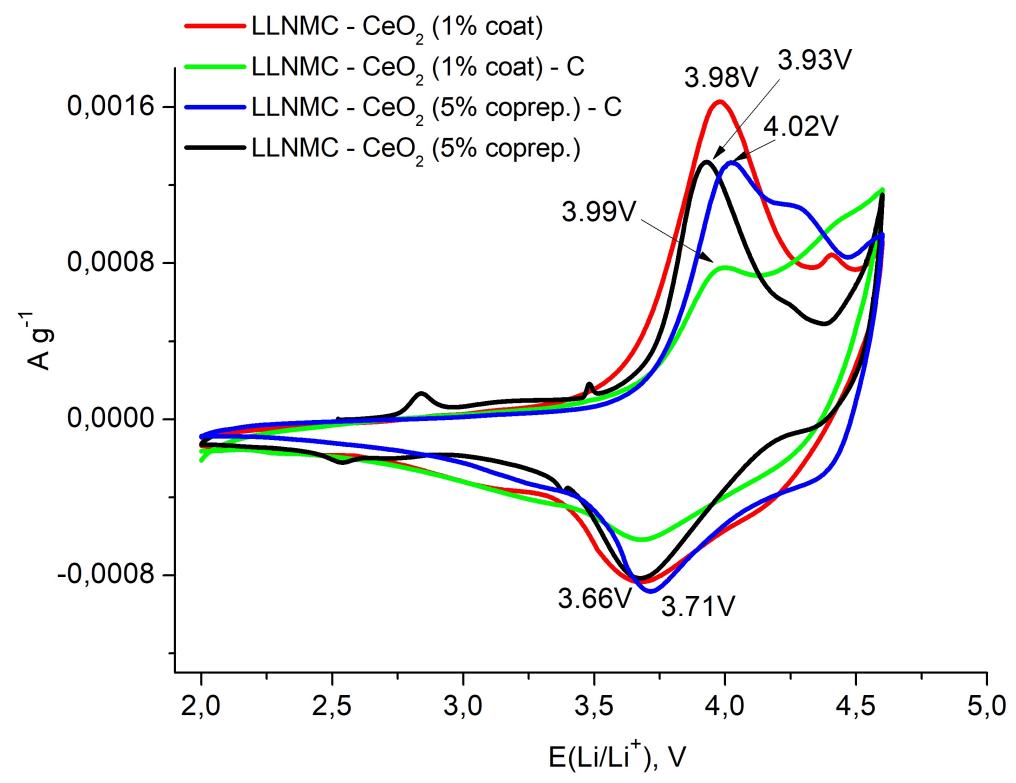

FIG. 3. Cyclic voltammograms at 2-nd cycle of various LLNMC-based composites

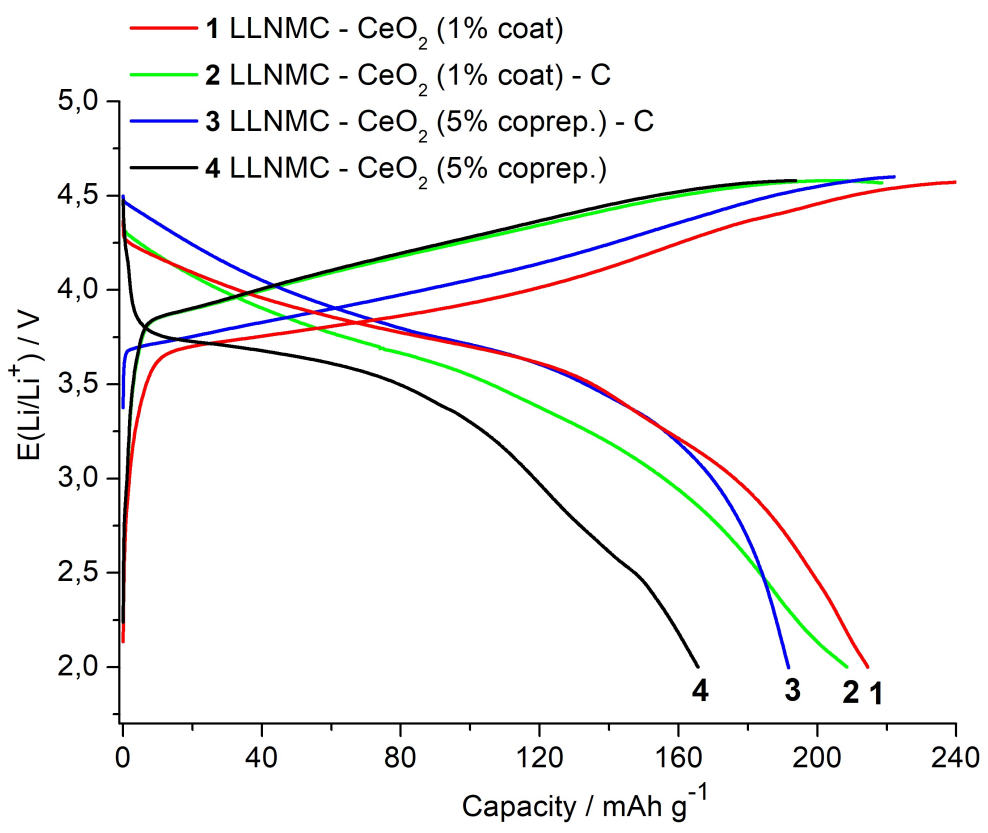

FIG. 4. Galvanostatic charge-discharge curves at 3-rd cycle of various LLNMC-based composites

by a significant increase in the total resistance of charge transfer and the surface layer. These features are absent in the Nyquist plots of other samples. The behavior of samples at $U>4.1 \mathrm{~V}$ is rather similar; the total charge transfer and surface layer resistance is decreased until $U=4.3-4.4 \mathrm{~V}$ followed by the drastic increase at $U>4.4(4.5) \mathrm{V}$.

It should be considered, that, according to Fig. 3, the most intense anionic redox processes occurred just in the sample $5 \%$ (coprep.)-C. Taking into account the previous considerations, the unusual increase in resistance of this sample could be also affiliated with anionic redox processes. It was recently found that intense redox processes in the anionic sublattice of LLNMC promote enhanced oxygen mobility during charge-discharge processes. Along with changes in $\mathrm{M}-\mathrm{O}$ distances due to the changes in the valence state of oxygen, these processes are accompanied also by the reversible and irreversible displacements of transition metals from their permanent positions in the cationic sublattice $[2,21,22]$. These displacements, in turn, result in the complicated lithium transport during 

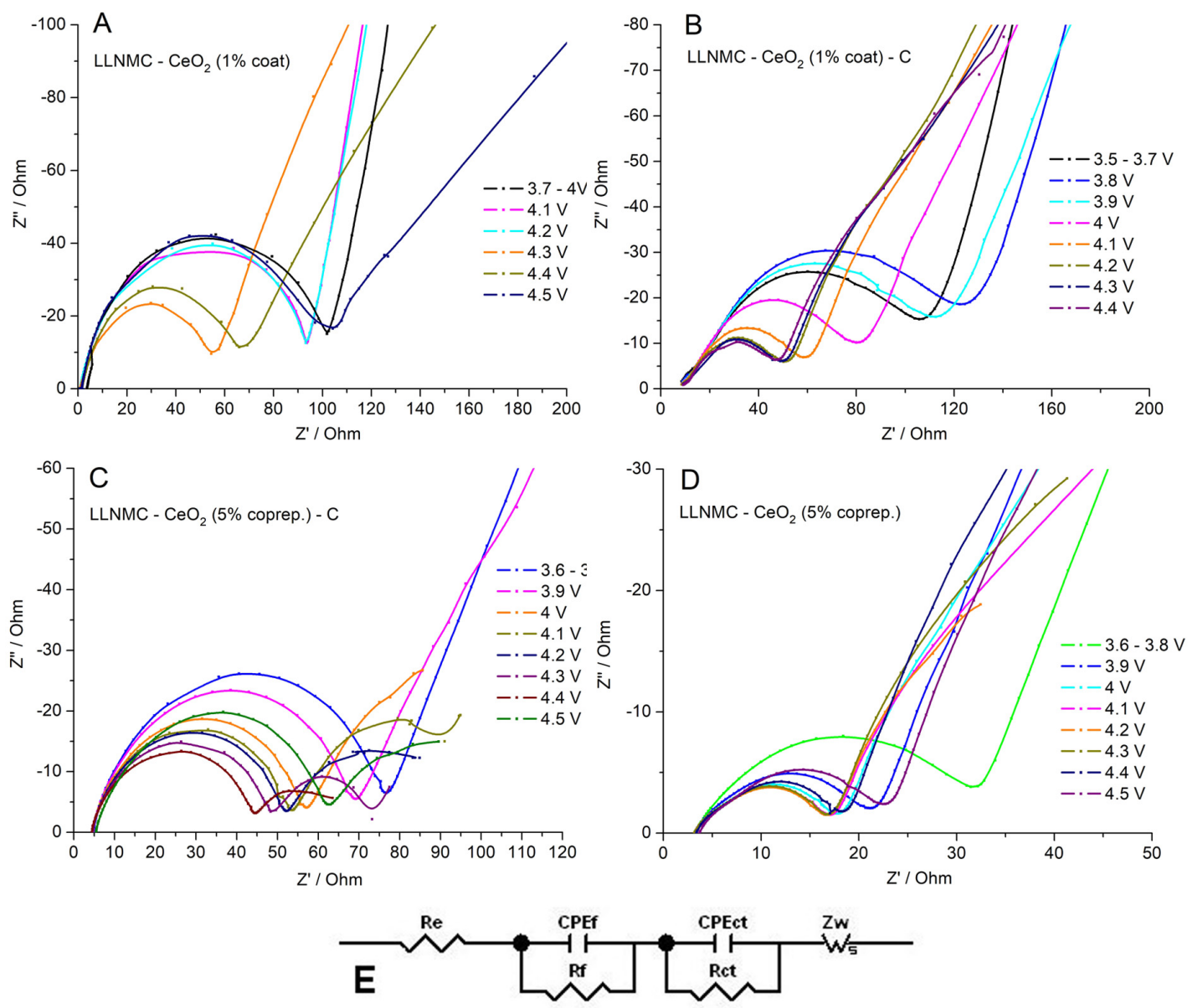

FIG. 5. (A-D) Nyquist plots of LLNMC-CeO 2 composites at various charge potentials; (E) The equivalent circuit used for the EI spectra fitting

charge-discharge processes and the additional polarization of electrodes. This polarization makes more difficult the charge transfer, thus increasing the charge transfer resistance. Less intense anionic redox processes in the LLNMC-CeO $\mathrm{C}_{2}$ composites obtained by coating and containing smaller amount of ceria could result in the lower cation displacement and, hence, the lower polarization of electrodes caused by this effect.

In order to calculate the apparent $\mathrm{Li}^{+}$diffusion coefficients from the impedance spectroscopy data, the following relationship was used [21]:

$$
D=\left(\frac{V_{m}}{\sqrt{2} n F s \sigma} \frac{d E}{d x}\right)^{2},
$$

where $\sigma$ is Warburg coefficient, Ohm s ${ }^{-0.5} ; F$ is Faraday constant, $96500 \mathrm{C} \mathrm{mol}^{-1} ; s$ is the surface of the electrode, $\mathrm{cm}^{2} ; V_{m}$ is specific molar volume and $d E / d x$ is the derivative of the potential versus intercalated/deintercalated lithium content. The Warburg coefficient was calculated from the slope of the effective part of Warburg impedance vs $\omega^{-0.5}(\omega=2 \pi v)$.

As it can be seen (Fig. 6), the lowest values of $\mathrm{Li}^{+}$diffusion coefficient are observed for the composite LLNMC-5 \%(coprep) at almost any potential. It could be affiliated both with the lack of conducting carbon coating, promoting the depolarization of the electrode/electrolyte interface during cycling and with the larger amount of poorly conducting ceria particles among the LLNMC grains. Coating with carbon and the reduction of the amount of ceria result in the significant increase in $D$ for LLNMC-5 \%(coprep)-C and, especially, for LLNMC-1 \%(coat) and LLNMC-1\%(coat)-composite. However, these enhanced $D$ values are also affiliated with ceria doping, as $\mathrm{Li}^{+}$diffusion coefficient of the undoped LLNMC obtained at the same synthesis conditions is the lowest in this series [15].

In order to explain this discrepancy, we have to note that the anionic redox could have two different effects on the transport of lithium ions. Along with negative effect briefly described above, the change in the oxygen 


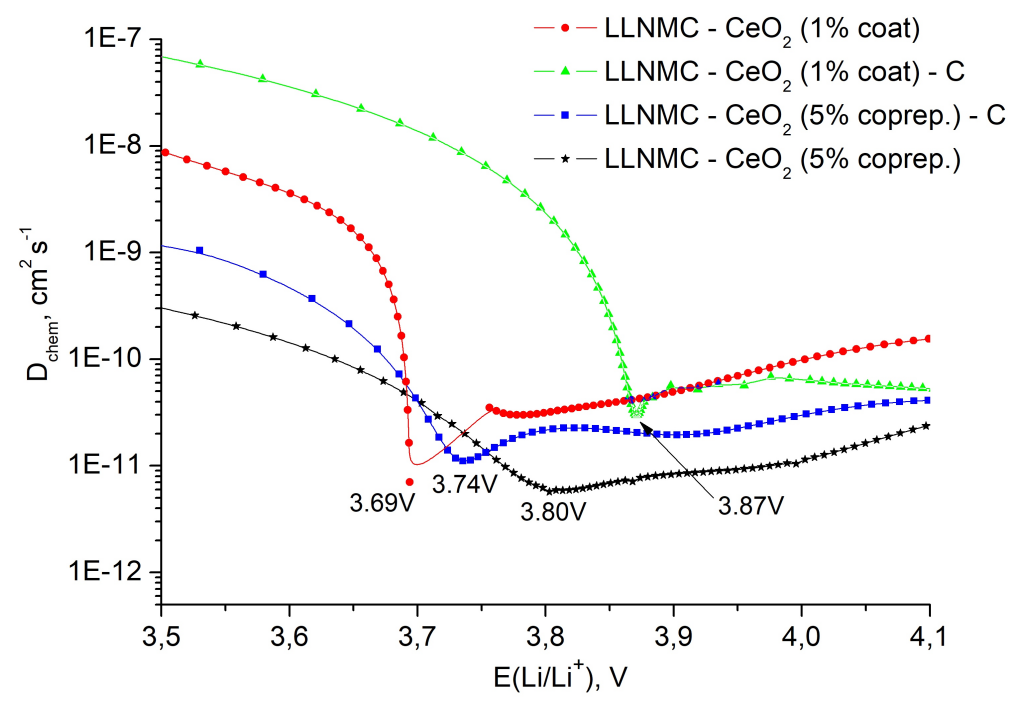

FIG. 6. The variation of $\mathrm{Li}^{+}$diffusion coefficients during the charge of various $\mathrm{LLNMC}-\mathrm{CeO}_{2}$ composites

valence state at high potentials during cycling and, hence, the appearance of nonbonding $\mathrm{O}^{n-}$ species might also promote the faster lithium ion diffusion through the LLNMC lattice [22]. It is known also that ceria is well known catalyst for oxidation processes; this catalytic effect could explain the activation of anionic redox processes in LLNMC by ceria particles even at $U \leq 4.6 \mathrm{~V}$ [14]. Taking into account these features, the higher $D$ values in the coated composites could be explained by the domination of the positive effect of the anionic redox processes on the lithium transport. The higher intensity of these processes at $U=4.1-4.6 \mathrm{~V}$ in LLNMC-5\%(coprep.) than in LLNMC-1 \%(coat) samples (Fig. 3) could be accompanied by the more intense cation displacement during cycling and, hence, result in the domination of the negative effect of the anionic redox on the $\mathrm{Li}^{+}$transport.

\section{Conclusions}

Analysis of the LLNMC-CeO ${ }_{2}$ composites obtained by different methods shows that the synthesis technique has little or no effect on their phase composition and morphology. In all cases in study the composites consisted of $200 \mathrm{~nm}$ LLNMC grains covered with $20-30 \mathrm{~nm}$ ceria particles. Coating of these samples with pyrolytic carbon results in the formation of nanocrystalline carbon film at the surface of composite particles. The electrochemical performance of carbon-free LLNMC doped with $5 \% \mathrm{CeO}_{2}$ by coprecipitation is different from other ones and close to the electrochemical behavior of common undoped LLNMC. Instead, the enhanced values of discharge capacity of other composites could not be explained by the charge compensation via redox processes in the cationic sublattice of LLNMC, as in common LNMC samples. The CV curves of these samples indicate the significant contribution of anionic redox processes at $U=4.1-4.6 \mathrm{~V}$ to the charge compensation mechanism during their cycling.

The higher charge transfer and surface layer resistance of the $5 \%$ (coprep)-C composite demonstrate that the most intense anionic redox-related anomalies in its $\mathrm{CV}$ curve could be associated with significant cation displacement observed by several authors during intense oxygen redox processes. However, the intensification of $\mathrm{Li}$ diffusion processes in the $1 \%$ ceria-coated samples with smaller but significant contribution of anionic redox during cycling could be also affiliated with anionic redox effects due to the formation of non-bonding oxygen species in the LLNMC lattice. Hence, the majority of ceria-related features of the electrochemical behavior of these composites could be explained by the various effects of redox processes in the anionic sublattice of LLNMC during cycling. The appearance of these phenomena at $U \leq 4.6 \mathrm{~V}$ is unusual for LLNMC and could be affiliated with the catalytic effect of the nanocrystalline ceria particles on the redox processes in the oxygen sublattice of LLNMC.

\section{Acknowledgement}

The work is partially supported by the individual grant 16-33-60195 (D. I. Petukhov) of the Russian Foundation for Basic Research. The authors are thankful to the M. V. Lomonosov Moscow State University Program of Development for the partial support of instrumental studies. 


\section{References}

[1] Li W., Song B., Manthiram A. High-voltage positive electrode materials for lithium-ion batteries. Chem. Soc. Rev., 2017, 46, P. 3006-3059.

[2] Erickson E.M., Schipper F., Penki T.R., Shin J.Y., Erk C., Chesneau F.F., Markovsky B., Aurbach D. Review-Recent Advances and Remaining Challenges for Lithium Ion Battery Cathodes. II. Lithium-Rich, $\mathrm{xLi}_{2} \mathrm{MnO}_{3} \cdot(1-\mathrm{x}) \mathrm{LiNi}_{a} \mathrm{Co}_{b} \mathrm{Mn}_{c} \mathrm{O}_{2}$. J. Electrochem. Soc., 2017, 164, P. A6341-A6348.

[3] Koga H., Croguennec L., Menetrier M., Mannessiez P., Weill F., Delmas C., Belin S. Operando Xray Absorption Study of the Redox Processes Involved upon Cycling of the Li-Rich Layered Oxide $\mathrm{Li}_{1.20} \mathrm{Mn}_{0.54} \mathrm{Co}_{0.13} \mathrm{Ni}_{0.13} \mathrm{O}_{2}$ in Li Ion Batteries, J. Phys. Chem. C, 2014, 118, P. 5700-5709.

[4] Lu Z., Dahn J.R. Understanding the Anomalous Capacity of $\mathrm{Li} / \mathrm{Li}\left[\mathrm{Ni}_{x} \mathrm{Li}_{(1 / 3-2 x / 3)} \mathrm{Mn}_{(2 / 3-x / 3)}\right] \mathrm{O}_{2}$ Cells Using In Situ X-Ray Diffraction and Electrochemical Studies, J. Electrochem. Soc., 2002, 149, P. A815-A822.

[5] Johnson C.S., Kim J-S., Lefief C., Li N., Thackeray M.M. The significance of the $\mathrm{Li}_{2} \mathrm{MnO}_{3}$ component in 'composite' $\mathrm{xLi} 2 \mathrm{MnO}_{3}(1-$ $\mathrm{x}) \mathrm{LiMn}_{0.5} \mathrm{Ni}_{0.5} \mathrm{O}_{2}$ electrodes, Electrochem. Comm., 2004, 6, P. 1085-1091.

[6] Thackeray M.M. Kang S.-H., Johnson C.S. Vaughey J.T., Benedek R., Hackney S.A. Li $\mathrm{MnO}_{3}-\mathrm{stabilized} \mathrm{LiMO}_{2}(\mathrm{M}=\mathrm{Mn}$, Ni, Co) electrodes for lithium-ion batteries. J. Mater. Chem., 2007, 17, P. 3112-3125.

[7] Sathiya M., Rousse G., Ramesha K., Laisa C.P., Vezin H., Sougrati M.T., Doublet M-L., Foix D., Gonbeau D., Walker W., Prakash A.S., Ben Hassine M., Dupont L., Tarascon J-M. Reversible anionic redox chemistry in high-capacity layered-oxide electrodes. Nature Mater, 2013, 12, P. 827-835.

[8] Oishi M., Yogi C., Watanabe I., Ohta T., Orikasa Y., Uchimoto Y., Ogumi Z. Direct observation of reversible charge compensation by oxygen ion in Li-rich manganese layered oxide positive electrode material, $\mathrm{Li}_{1.16} \mathrm{Ni}_{0.15} \mathrm{Co}_{0.19} \mathrm{Mn}_{0.50} \mathrm{O}_{2}$. J. Power Sources, 2015, 276, P. 89-94.

[9] Luo K., Roberts M. R., Hao R., Guerrini N., Pickup D.M., Liu Y.-S., Edstrom K., Guo J., Chadwick A.V., Duda L.C., Bruce P.G., Charge-compensation in 3d-transition-metaloxide intercalation cathodes through the generation of localized electron holes on oxygen. Nature Chem., 2016, 8, P. 684-691.

[10] Saubanere M., McCalla E., Tarascon J.-M., Doublet M.-L. The Intriguiging Question of Anionic Redox in High-Energy Density Cathodes for Li-ion Batteries. Energy Environ. Sci., 2016, 9, P. 984-991.

[11] He F., Wang X., Du C., Baker A.P., Wu J, Zhang X. The effect of samaria doped ceria coating on the performance of $\mathrm{Li}_{1.2} \mathrm{Ni}_{0.13} \mathrm{Co}_{0.13} \mathrm{Mn}_{0.54} \mathrm{O}_{2}$ cathode material for lithium-ion battery. Electrochim. Acta, 2015, 153, P. $484-491$.

[12] Li G.R., Feng X., Ding Y., Ye S.H., Gao X.P. AlF 3 -coated $\mathrm{Li}\left(\mathrm{Li}_{0.17} \mathrm{Ni}_{0.25} \mathrm{Mn}_{0.58}\right) \mathrm{O}_{2}$ as cathode material for Li-ion batteries. Electrochim. Acta, 2012, 78, P. 308-315.

[13] Liu K., Yang G-L., Dong Y., Shi T., Chen L. Enhanced cycling stability and rate performance of $\mathrm{Li}\left[\mathrm{Ni}_{0.5} \mathrm{Co}_{0.2} \mathrm{Mn}_{0.3}\right] \mathrm{O}_{2}$ by CeO ${ }_{2}$ coating at high cut-off voltage. J. Power Sources, 2015, 281, P. 370-377.

[14] Kurilenko K.A., Shlyakhtin O.A., Petukhov D.I., Garshev A.V. Catalytic effect of nanostructured $\mathrm{CeO}_{2}$ coating on the electrochemical performance of $\mathrm{Li}(\mathrm{Li}, \mathrm{Ni}, \mathrm{Mn}, \mathrm{Co}) \mathrm{O}_{2}$. Solid State Ionics, 2018, 324, P. 59-64.

[15] Kurilenko K.A., Shlyakhtin O.A., Petukhov D.I., Garshev A.V. Effect of $\mathrm{CeO}_{2}$ coprecipitation on the electrochemical performance of $\mathrm{Li}(\mathrm{Li}, \mathrm{Ni}, \mathrm{Mn}, \mathrm{Co}) \mathrm{O}_{2}-\mathrm{CeO}_{2}-\mathrm{C}$ composite cathode materials, J. Power Sources, 2017, 354, P. 189-199.

[16] Wu F., Wang M., Su Y., Bao L., Chen S. Surface of $\mathrm{LiCo}_{1 / 3} \mathrm{Ni}_{1 / 3} \mathrm{Mn}_{1 / 3} \mathrm{O}_{2}$ modified by CeO ${ }_{2}$-coating, Electrochim. Acta, 2009, 54, P. 6803-6807.

[17] Yuan W., Zhang H.Z., Liu Q., Li G.R., Gao X.P. Surface modification of $\mathrm{Li}\left(\mathrm{Li}_{0.17} \mathrm{Ni}_{0.2} \mathrm{Co}_{0.05} \mathrm{Mn}_{0.58}\right) \mathrm{O}_{2}$ with CeO ${ }_{2}$ as cathode material for Li-ion batteries. Electrochim. Acta, 2014, 135, P. 199-207.

[18] Xu Y., Li X., Wang Z., Guo H., Peng W., Pan W. The enhanced high cut-off voltage electrochemical performances of $\mathrm{LiNi}_{0.5} \mathrm{Co}_{0.2} \mathrm{Mn}_{0.3} \mathrm{O}_{2}$ by the $\mathrm{CeO}_{2}$ modification, Electrochim. Acta, 2016, 219, P. 49-60.

[19] Assat G., Tarascon J.-M. Fundamental understanding and practical challenges of anionic redox activity in Li-ion batteries. Nature Energy, 2018, 3, P. 373-386.

[20] Xu J., Sun M., Qiao R., Renfrew S.E., Ma L., Wu T., Hwang S., Nordlund D., Su D, Amine K., Lu J, McCloskey B.D., Yang W., Tong W., Elucidating anionic oxygen activity in lithium-rich layered oxides, Nature Comm., 2018, 9, P. 947.

[21] Levi M.D., Salitra G., Markovsky B., Teller H., Aurbach D., Heider U., Heiderb L. Solid-State Electrochemical Kinetics of Li-Ion Intercalation into $\mathrm{Li}_{1-2 x} \mathrm{CoO}_{2}$ : Simultaneous Application of Electroanalytical Techniques SSCV, PITT, and EIS. J. Electrochem. Soc., 1999, 146, P. 1279-1289.

[22] Zhao S., Sun B., Yan K., Zhang J., Wang C., Wang G. Aegis of Lithium-Rich Cathode Materials via Heterostructured LiAlF 4 Coating for High-Performance Lithium-Ion Batteries. ACS Appl. Mater. Interfaces, 2018, 10, P. 33260-33268. 